\title{
Addressing Uncertainty in Economics and in the Economy
}

\author{
Sheila C Dow
}

\begin{abstract}
This paper explores the way in which society in general and economists in particular deal with fundamental uncertainty. It is argued that uncertainty is interdependent with the evolution of institutions and behavior, including that designed to help society cope with uncertainty. While some mainstream theory does address uncertainty, it employs a much narrower concept than fundamental uncertainty. But generally, in spite of the evident increase in fundamental uncertainty during the crisis, most mainstream theory ignores it. While ignoring uncertainty can at times be a successful coping mechanism, it is argued that, as a blanket coping mechanism, ignoring uncertainty seriously limits the realism of theory and therefore also practice and policy. It is concluded that economists should embrace uncertainty by tailoring methodologies and theories to address it. This would provide a more fruitful basis for policy aimed at reducing uncertainty in the economy and also reducing our own uncertainty.
\end{abstract}

JEL classifications: B40, B50, D80

Keywords: uncertainty, open systems, financial behaviour

\author{
Division of Economics \\ University of Stirling \\ Stirling FK9 4LA \\ Scotland, UK \\ e-mail: $\underline{\text { s.c.dow@stir.ac.uk }}$ \\ and \\ Department of Economics \\ University of Victoria \\ 3800 Finnerty Road \\ Victoria, BC V8P 5C2 \\ Canada
}

November 2013 


\section{Introduction}

The crisis saw a marked increase in uncertainty in economic life, but much of economic theory continues to preclude it. This is in stark contrast to the centrality of uncertainty in Keynes's thinking and its relevance to the crisis, as explained by Skidelsky $(2009,2011)$. While there has been a revival of interest in Keynesian fiscal solutions to the crisis, little attention is paid to the way in which Keynesian uncertainty theory offers an explanation for the crisis and thus guidance as to prevention, or at least mitigation, of future crises. Some of the resistance to renewing attention to Keynes's theory of uncertainty is reasoned, as in Stiglitz's (2010) argument that other factors provide better explanations. But generally it is left implicit. The purpose of this paper is to use Keynes's theory of uncertainty to explore, not only how uncertainty and perception of uncertainty evolve in society in general, but also how they evolve among economists themselves.

Much of the standard mainstream economics and finance literature ignores uncertainty by conflating it with quantifiable risk. Even though it may be accepted that risk cannot be quantified in general in objective terms, nevertheless it is argued, according to the Subjective Expected Utility model, that we have the capacity to make subjective probability estimates, so that unquantifiable risk is no longer relevant. The ambiguity and new behavioural economics literatures have attempted to take uncertainty more seriously (in the Knightian tradition) as unquantifiable risk. These analyses have pointed to substantive effects of uncertainty and uncertainty aversion, particularly on financial markets. It is explored here how limited these Knightian treatments of uncertainty are compared with Keynesian 'fundamental' uncertainty in terms of explaining the role played by uncertainty in the emergence of the crisis. A critical 
difference is the endogenous nature of Keynesian uncertainty, such that it evolves with the structural and behavioural changes designed to mitigate uncertainty; we explore these mechanisms and how far they have been successful. Particular emphasis is placed on the degree to which uncertainty is acknowledged in the economy and among economists (building on Dow 1995). The paper concludes with a discussion of uncertainty, in an open-system framework, as something other than being simply a source of distortion. The discussion encompasses both uncertainty in the economy and uncertainty among economists.

\section{The Source, Nature and Consequences of Uncertainty}

Fundamental uncertainty with respect to beliefs, as explored by Keynes (1921), arises from the openness (organicness) of the economic system whereby the future is not even in principle knowable. The ultimate source of uncertainty is therefore the nature of the subject matter, such that uncertainty is aleatory. ${ }^{1}$ Conventions and institutions evolve and behaviour may be creative, such that the units of analysis and their interrelations are not predetermined and the structure within which these interrelations occur is itself not predetermined. In Lawson's (1997) words, there is neither intrinsic nor extrinsic closure. ${ }^{2}$ Keynes (1921) argued that an absence of quantifiable probabilities was therefore the general case. Nevertheless there was scope for ordinal probabilities and even postulating a reasonable cardinal range for probabilities. As Keynes (1921: 176) put it: 'Many probabilities, which are incapable of numerical measurement, can be placed nevertheless between numerical limits. And by taking particular non-numerical probabilities as standards a great number of comparisons or approximate measurements become 
possible.' That these are not calculations based as if on probability distributions is evidenced by the fact that insurance brokers can quote such a wide range of prices even on fairly conventional risks (Feduzi, Runde and Zappia 2012). Rather than a binary divide between risk and uncertainty whereby uncertainty amounts to ignorance, Keynes's argument implies that judgement about risk is possible (in some degree) when seeking a basis for action. Keynes's policy prescriptions were then addressed to reducing uncertainty, not just when it is most evident in a crisis, but in the longer-run. He proposed altering the economic environment, not only with stabilisation policy but also with institutional change which would reduce uncertainty (Keynes 1926). This followed from his argument that the conditions for uncertainty are always present, not just when uncertainty is most evident.

It is at times of crisis that attention is drawn more widely to uncertainty, and indeed uncertainty may vary in intensity over time. At times of crisis the basis for judgement may be so weak that there is an unwillingness to set prices altogether (or as Runde, 1995, puts it, an unwillingness to place bets in the standard subjectivist Bayesian framework). Within a given structure, uncertainty varies with the degree of confidence in expectations which in turn varies with the weight of relevant evidence. But the conceptualisation of weight itself may vary, for example as new evidence reveals new realms of ignorance (Runde 1990). More generally, what is regarded as relevant evidence and how it impacts on expectations depends on the prevailing understanding of economic processes, but these are open to change, not only in the evidence but also in willingness to admit evidence and to admit to uncertainty (Dow 1995). Fundamental uncertainty in Keynes's sense is an objective outcome of logical relations between theory and evidence, 
but is subjective in that these logical relations hold differently from different perspectives, including the attitude taken to uncertainty. Differing degrees of willingness to admit more or less limited forms of uncertainty are represented not only in the economy but also among economists themselves.

Mainstream economic and finance theory is generally characterised as not admitting fundamental uncertainty at all; where the term 'uncertainty' is used the actual meaning is generally quantifiable risk. This accords with a closed-system approach to theorising, whereby variables are classified as endogenous or exogenous; endogenous variables interact in a predetermined way within a given structure, while exogenous variables are known to be random. This theoretical system is based on a closed-system ontology in the sense that structure, changes in structure and interrelations within the structure are all knowable within quantifiable probability distributions (see Lawson 1997). Any disturbances take the form of shocks to this system, where the shocks are known to be stochastic.

But uncertainty is increasingly being considered as a source of disturbance. For example it has been identified as following on from shocks and can therefore be analysed itself as a shock (see e.g. Bloom 2009). The microeconomic underpinnings of such an approach have been developed in two literatures which take on board the possibility that conditions do not allow probability to be quantified: the new behavioural economics and the ambiguity approach to decision theory. Rather than quantifiable risk, uncertainty for these approaches is presented in the Knightian (1921) sense of unquantifiable risk, i.e. an absence of quantifiable probabilities, and therefore ignorance. Behavioural economics shifts the focus from rational choice, which requires quantifiable probability-based 
beliefs, to psychology as the basis for beliefs (see e.g. Barbaris and Thalrers' 2003, review). Experimental evidence has supported the view (stemming from the work of Kahneman and Tversky 1974) that subjects suffer from cognitive limitations on making judgements (e.g. with respect to probabilities) on which to base rational choice. They therefore resort to reliance on heuristics which introduce biases relative to the predictions of standard decision theory. Experiments generally supply subjects with the information necessary for making calculations, focusing therefore on information processing errors. But, even if they had adequate calculative capabilities, epistemic uncertainty may also arise in non-experimental situations if the information that is necessary for making probability calculations is inaccessible. ${ }^{3}$ This inaccessibility may be opportunistically wilful (as among borrowers concealing their risk from lenders, or in the opaqueness of structured products), the outcome of institutional arrangements (as in the incentives for credit-rationing agencies to distort their risk assessment), or it may simply be temporary, being resolved as events unfold and new information emerges, or as learning occurs.

The ambiguity literature, built on Ellsberg's (1961) experimental work on choice where even subjective information on some probabilities is unavailable, similarly identifies behaviour which deviates from standard rationality. As with behavioural economics, ambiguity theory refers to Knightian uncertainty (see Dequech's, 2000, critique). The driving force is aversion to ambiguity, which poses a challenge to Bayesian theory with such results as an absence of trades or an unwillingness to take a position (see e.g. Dow and Werlang 1992 and Bewley 2002). Uncertainty about the subjective probabilities of Bayesian theory may arise from concealed information, or from uncertainty as to the correct model by which to process information (see e.g. Drechsler 
2013). The psychology literature also suggests that ambiguity may arise with respect to the meaning attached to propositions, i.e. 'semantic' uncertainty (Lane and Maxfield 2005). This further source of uncertainty has been a particular focus of monetary authorities in their attempts to communicate their expectations and the reasoning behind them. Elimination of semantic uncertainty is seen as requiring only increased transparency as a mechanism for reducing information asymmetries, thus facilitating rational choice (Dow, Klaes and Montagnoli 2007).

For all these literatures, just as the benchmark for choice is rationality, the benchmark for information is full (frequency distribution) information which is, in principle at least, knowable, implying a closed-system ontology. Camerer and Weber (1992: 330) define ambiguity as 'uncertainty about probability, created by missing information which is relevant and could be known'. True objective probabilities (i.e. true measures of risk) and thus true prices therefore exist in principle. The notion of relevance is also taken to be objective such that even 'unknown unknowns' (unpredicted possibilities) would have been revealed by unconstrained information of the deterministic processes within a closed-system economy, even if only as disturbances known to be stochastic. Uncertainty is treated as a given outcome of an exogenous constraint on full information.

Fundamental uncertainty differs from these mainstream meanings of uncertainty in important respects. Of primary importance is the fact that Keynesian uncertainty arises from the openness of the economic system and is thus not even in principle eliminable, whether or not in crisis situations. If the range of future possibilities cannot be known, it is impossible logically to assign even subjective probability estimates which sum to one 
(even without ambiguity aversion). There is no such thing as 'true risk' or a 'true price' as benchmarks for market fluctuations (Townshend 1937; see further Dow 2013). Second uncertainty is not fixed exogenously (or stochastic), but is open to the exercise of judgement and some knowledge. The emergence of unknowable unknowns is to be expected, and yet some knowledge may be brought to bear (see Runde 2009). Further fundamental uncertainty varies in intensity and can be reduced by appropriate change in institutions and conventions (or increased by inappropriate change). Similarly the degree to which uncertainty is admitted and the attitude to it are not given in Keynesian uncertainty theory, but rather can vary as between different groups and also over time. Far from being the given consequence of an exogenous constraint on knowledge, as the dual of certainty, fundamental uncertainty is endogenous to behaviour and to structure, can vary in intensity and is open to degrees of recognition.

These differences are material to how far uncertainty may be said to have been fundamental to the crisis. The incidence of uncertainty (in the sense of unquantifiable risk) during the crisis was widely acknowledged, aversion was expressed by financial markets and there was widespread incidence of missing markets. Behavioural and ambiguity theorists cite evidence of departures from the standard rationality model and explain some of the 'puzzles' in financial markets (i.e. departures from the standard rationality model) by uncertainty and uncertainty aversion. Indeed Boyarchenko (2013) derives evidence on changes in uncertainty aversion over time during the crisis. But, while some of the verbal analysis in this literature can often be illuminating, it has proved difficult to incorporate its insights into formal general equilibrium macroeconomic models in order to explain changes in uncertainty and uncertainty aversion. 
The consequence of retaining the benchmark of fully-informed rational behaviour, e.g. on the part of finance specialists, has also limited the scope for explaining the onset of the crisis. The 'uncertainty shock' literature sees uncertainty being caused by other shocks, causing instability and potentially a crisis when amplified by (irrational) herd behaviour. But it is the initial shock which is the cause, and uncertainty is gradually dispelled as new information emerges. The analysis and policy implications all focus on the factors which disturbed equilibrium and impeded market forces from restoring equilibrium, notably incomplete information. The expectation then is for successful policy to promote a return to normal market conditions, with no expectation of a future crisis unless new forms of constraint (especially on information) emerge. More importantly, while these theories pick up features of behaviour around the time of crisis, they do not explain the long build-up to the crisis through a period of apparent stability (see further Frydman and Goldberg 2011, especially ch. 6, for an extended analysis).

Within a Keynesian framework, pricing in financial markets has no independent objective probabilistic basis, given the general absence of quantifiable probabilities. Pricing therefore draws on evidence interpreted according to some theory or other, with a strong element of conventional judgement which is vulnerable to discrete shifts. Minsky's (1986) Keynesian theory of financial instability sets out the process by which conventional expectations become more confidently held during an upswing (although the conditions for uncertainty continue to be present), such that planned investment increases and finance is more readily available, reinforcing this confidence. The multiplier-accelerator effects of this increased investment fuel economic expansion which lends further confidence to investment planning and its associated finance. This 
confidence encourages ever-increasing leverage and therefore ever-increasing fragility of the financial structure and also the diversion of activity into speculative markets and away from production. It is the fragility rather than the particular event which punctures confidence in expectations which brings on the eventual crisis. Indeed it was financial stability which bred instability. Increased awareness in retrospect of the flimsy basis for the confident expectations of the boom phase increases uncertainty, with the result of heightened liquidity preference across all sectors, further fuelling the crisis (Bibow 2009). The absence of a benchmark of true prices as a guide to behaviour is thus fundamental to financial instability. The associated uncertainty is endemic to the market process and is thus at the core of the generation of crisis. Those who employed a Minskyan analysis therefore anticipated a crisis, although the framework explains why the timing and particular character of any crisis are not determinate.

Keynes's argument about the generality of uncertainty extended to its domain among economists as well as economic agents (Dow 2003). Just as agents face fundamental difficulties in forming quantitative probabilistic expectations, so do economists face uncertainty in their own forecasting. Keynes showed how uncertainty can vary in degree, depending on the relative amount of relevant evidence which can be brought to bear on a probabilistic judgement. But relevance in turn depends on a theoretical perspective which is itself subject to varying degrees of confidence. Indeed the economist's uncertainty about the validity of models being employed has been the subject of the (mainstream) model uncertainty literature (see e.g. Hansen and Sargent 2001). However model uncertainty is only addressed there in a limited way (Dow 2004). Either uncertainty is applied to the choice between a limited range of existing models, or 
else it is captured in a stochastic error distribution. Being calculative, these analyses of uncertainty in fact refer instead to quantifiable risk. Indeed the methodological framework within which mainstream economics focuses on calculative rationality supports the presumption that there is one best (or even true) model of the economy (arrived at through the calculative rationality of economists themselves). It is within this context that many economists responded to the crisis initially by opening up to different ideas (like a return to a Keynesian theory of aggregate demand), but then retreated into variations of pre-crisis thinking. The question was posed in terms of the calculative search for a better model, rather than considering whether a single deductivist formal model is in fact the best way of formulating economists' knowledge (Lawson 2009).

\section{Mechanisms for Coping with Uncertainty}

Uncertainty may vary in degree, such that there can be significant periods during which uncertainty is relatively low. This could be said of the Great Moderation period which pre-dated the crisis, for example. Does this mean that uncertainty is only significant temporarily, as a consequence of crisis (even as an exogenous shock)? Was the crisis just a Minskyan 'moment' (Amariglio and Ruccio 1995; Whalen 2007)? But to regard a crisis as a temporary aberration is to reflect the mainstream closed-system approach, whereby the norm is gravitation to a stable equilibrium. From this perspective, uncertainty is only relevant, if at all, as a temporary exogenous source of anxiety and impediment to markets reaching equilibrium. This contrasts with Minsky's systemic analysis of the macro economy over time. 
But there are further reasons why it is inappropriate to limit considerations of uncertainty to times of crisis. Periods of stability in fact owe much to the mechanisms which have evolved over time to address uncertainty and which therefore have as much relevance during periods of stability as during periods of crisis. In this section we therefore consider the range of mechanisms which have evolved in response to uncertainty, changing the pre-existing ontology. Rather than considering uncertainty as some kind of periodic externally-generated shock or constraint, therefore, we will consider how it has helped to shape the institutions, practices and conventions which structure economic life and form the basis for future judgements about uncertainty.

Consideration of mechanisms (both epistemological and institutional) to cope with uncertainty goes back at least to Hume and Smith, who both had an ontologicallyfounded view of knowledge as being uncertain. Reason and evidence alone were rarely sufficient for knowledge, so reliance is placed on conventional understandings or belief, built up over long periods of experience. For Hume, the motivation for action, and indeed for seeking knowledge, was the passions. Keynes (1937) developed this argument, similarly integrating the emotions with cognition (Dow 2011). He identified reliance on the views of peers and the views of experts, as well as extrapolating from the past, as a way of both underpinning and supplementing reasoned argument drawing on evidence. But non-routine action required further the impetus from 'animal spirits' (Dow and Dow 2011).

New developments in psychology are contributing to our understanding of this relation between emotion and cognition. For example, the role of psychology in the study of behaviour in financial markets under uncertainty is approached by Tuckett, Chong and 
Ruatti (2012) from the starting point of Freudian psychoanalysis (see further Tuckett 2011). Supported by survey evidence from the financial sector, they explain the decision to act in spite of uncertainty as being based on judgements about market valuations mediated by the motivation to beat the market in some combination with fear of being beaten by the market. The justification for action is expressed in the form of a "conviction narrative' that presents an argument which is convincing in that it is in itself coherent. For Tuckett all knowledge is constructed so that these narratives are all fictional. But Keynes had argued that beliefs are formed by applying judgement to a combination of sources which include reason and experience. So it is a matter of the nature of the sources, the balance of their combination and the judgement applied to develop a coherent narrative. We can adapt Tuckett's ideas by drawing on Lawson's (1997) application of the term 'fiction' only to those assumptions that contradict (rather than simplify) our understandings of real experience. This useage allows for consideration of degrees of fictionality in the sense of how far a narrative contradicts understandings of real experience.

Simon $(1955,1986)$ had also introduced his notion of bounded rationality, not only on cognitive limitations but also on ontological grounds, that it is the open nature of social systems which limits the availability of information: 'the characteristics of the environment [of choice] and the interrelations of environment and organism [of choice]' (Simon 1955: 100). As Loasby (1989: 141) puts it, 'That the complexity of our environment, natural and artificial, extends far beyond the bounds of our rationality is the central fact with which Simon has been trying to deal throughout his career'. Simon therefore considered cognitive and informational limitations in a broader sense than 
Kahneman and Tversky's subsequent analysis. By identifying limitations on ontological grounds, he challenged the scope for calculative rationality itself. Simon pioneered the concept of heuristics (mental short-cuts) as an alternative to calculative rationality, providing a basis for behaviour under uncertainty, where rationality is bounded. ${ }^{4}$ Indeed, starting from evidence of the nature of actual decision-making rather than the benchmark of constrained optimisation, Simon saw heuristics in a positive light (not a constraint), as enabling decision-making under uncertainty, rather than a source of rigidity in mainstream choice theory (Earl 2012). This emphasis on the important positive role of heuristics has been developed further by Gigerenzer (see e.g. Gigerenzer 2007). ${ }^{5}$

Both Hume and Smith also discussed the role of legal structures (particularly those surrounding property rights and contracts) as a way of organising society which reduced uncertainty. Their work was a strong influence on Hayek (1960, 1973-9), for whom social order arose, not through deliberate action, but through the unintended consequences of habitual action on the part of individuals, including the endogenous emergence of institutions. Again, what appears in choice theory as a rigidity is in this view something which serves to reduce uncertainty and thus encourage action. The emergence of institutions more generally can be understood as a means of reducing uncertainty (see further Hodgson 1988). The existence of the firm itself (indeed of any contractual arrangement) can be understood as a mechanism to reduce uncertainty for some parties involved, providing a pool of liquidity and a basis for action (Loasby 2011). As Coase (1937: 22) put it 'It seems improbable that a firm would emerge without the existence of uncertainty'. Within the firm, further, particular strategies are developed to aid decision-making under uncertainty; scenario planning, for example, is a methodology 
which has proved to be very helpful in practice for forming judgments within the firm in the face of uncertainty (Jefferson 2012).

More widely market relations depend on the support of the state and the gradual build-up of non-calculative trust (uncertainty precluding calculation). The banking system in particular operates on trust, allowing a fractional reserve system which produces money, which underpins all other market institutions (Davidson 1972). Keynes discussed liquidity preference in terms of the demand to hold money because it is the safest asset to hold when uncertainty is high. But the institutional structure which produces money has evolved over time, with money assets having varying capability to address uncertainty. As we saw in the crisis, some features of this evolution undermined confidence in money assets. Sometimes the policy changes introduced to reduce the incidence of crisis in the future may have the reverse effect. For example the introduction of capital adequacy requirements in the 1980s encouraged the securitisation and derivatives activities which fuelled the current crisis (Chick 2013). Among financial institutions themselves financial products such as derivatives and credit default swaps were developed to reduce uncertainty, although in aggregate the effect turned out to be the increase in uncertainty on the onset of crisis.

Given that so much of the structure within which markets operate, therefore, is the product of long experience of uncertainty, uncertainty is a factor to take into account as a long-term phenomenon in addition to its short-term variations. But periods of crisis and thus of increased uncertainty can often prompt structural shifts. These developments may be designed to reduce the chances of a recurrence of crisis and thus high levels of uncertainty, such as changes in relations between banks and the central bank following a 
banking crisis. There is a ratchet effect, such that these institutional arrangements continue beyond the crisis and condition the experience in the build-up to the next crisis. This was the thinking behind Keynes's approach to monetary policy, which was to prioritise the promotion of financial stability (Tily 2007). But sometimes crisis situations can disrupt longstanding conventions and institutions, as when confidence is destroyed or large institutions fail.

Tuckett, Chong and Ruatti (2012) explain the scope for profit-seeking behaviour in financial markets as arising from the same conditions that generate uncertainty. But the financial crisis arguably stemmed from mechanisms which fostered over-confidence in expectations as to risk and return, that is, an inappropriate inattention to uncertainty. Tuckett (2011) explains this phenomenon in terms of Freudian psychoanalysis applied to the emotional aspects of financial behaviour: 'as human beings we deal with such conflicting feelings by making the painful ones unconscious; we behave as though we never thought or felt whatever it is we don't like' (Tafler and Tuckett 2007: 19). Tuckett explains excessive upswings in asset values in terms of pursuit of the 'phantastic object', suppressing reason grounded in evidence. The resulting theory of emotional finance has provided an interpretation of survey evidence of the emotional withdrawal from uncertainty into fear (see also Gordon 2003: 111). The conviction narratives which Tuckett, Chong and Ruatti (2012) identify as being necessary to enable action under uncertainty inevitably require more than reason and evidence (just as Hume had argued). But these narratives can deviate unduly from reason and evidence when focused on a 'phantastic object'. In terms of our discussion above, the degree of fictionality in the narratives used to justify action increases. Such narratives in turn may be the source, 
further, of semantic uncertainty when they provide accounts which conflict with other accounts, particularly reality-based accounts. But there may be a strong motivation to avoid such uncertainty. Cognitive dissonance arising from conflicting constructions put on experience is uncomfortable, encouraging the reaction of denial (Earl 1992).

A powerful conflict of narratives is provided by the fact that financial markets have relied increasingly on quantitative models which exclude uncertainty, limiting scope for judgement, while the experience of uncertainty became palpable in the crisis. We know that individual traders are aware of some of the limitations of quantitative models (McKenzie 2006, Tuckett 2011). But this awareness extended only to the scope for 'mispricing' relative to a correct price, and thus the scope for trading opportunities. Strategy in the financial sector in the run-up to the crisis arguably was shaped by institutional narratives that were unduly influenced by the excessive confidence which arose from a basic modelling approach which ignored uncertainty. Indeed this modelling approach was institutionalised by the very capital adequacy requirements which were intended to reduce risk. The mechanism which therefore evolved in financial markets to address uncertainty in the run-up to the crisis was denial.

Uncertainty-denial may be enabling in some contexts, e.g. when it comes to entrepreneurial action. Indeed Keynes (1936: ch. 11, 12) pointed out that a rational (in the mainstream economics sense) investor would never have sufficient basis for action. But suppressing awareness of uncertainty can be counterproductive when it encourages suppression of reason and evidence. The institutional arrangements which had evolved over a long period to address uncertainty had steadily been dismantled since the 1970 s (Chick 2008 and 2013), leaving markets vulnerable to the onset of crisis which, rather 
than a random shock, was the systematic outcome of behaviour governed by denial of uncertainty. This proved not to be a successful coping mechanism since the outcome was a debilitating level of uncertainty.

Economists, like every other group, are exposed to uncertainty and have forged their own ways of coping with it. If indeed the subject matter is open and evolving, then, as Hume, Smith and Keynes had argued, our knowledge about it is in general uncertain. Indeed Smith (1795) argued that it was uncertainty prompted by novel events (what he called 'wonder') which motivated scientific enquiry; this was a psychological drive to set the mind at rest by finding patterns, through making new connections, which made sense of new phenomena. While it was recognised that knowledge was uncertain, uncertainty was ignored in the sense that scientific enquiry proceeded anyway, but was acknowledged in the recognition that theories could not be demonstrated as true. ${ }^{6}$ The study of economics can be understood therefore as an attempt to reduce our uncertainty about the economy.

Faced with uncertainty, economists have developed conventions as to how best to reduce it, but, as with the economy, these conventions can be more or less successful. The dominant convention, which has gained force over the last fifty years, is to build theory within a formal deductivist framework. The resulting models are based on axioms about optimising behaviour on the part of individual agents, where (frequencydistribution-based) information is held with certainty (or certainty equivalence). The recent literature has introduced modifications with respect to knowledge being concealed (asymmetric information), aversion to such concealment, and cognitive capacities being limited. Chick (1995) has analysed this closed-system approach in terms of its dualism, 
drawing on Prigogine's critique of traditional science. Science had been understood as a means of identifying the order underlying apparent chaos. This 'mechanistic, linear approach that has pervaded the course of science over the past 350 years has led to the glorification of order and the subsequent objectification of reality. At the same time, the idea of mystery—a sense of the unknowable — has typically been dismissed by science as mere metaphysics or, worse, superstitious ignorance - the last refuge of a primitive mind' (Gordon 2003: 100).

To think, as we have done here, of economic methodology in terms of conventions for coping with uncertainty is to reflect the conclusions from the philosophy of science that there is no demonstrably best methodology of science. Rather, communities of scientists develop methodologies which make most sense to them in relation to the way in which they understand the subject matter (their ontology), perpetuate it through 'normal science' and propagate it through education. Nonmainstream approaches to economics, which have different ontologies, have therefore developed different conventions from mainstream economics. Post Keynesians for example have put uncertainty at the core of their theory, seeing it as an essential feature of the economic process. As a result, just as economic agents employ a range of methods to build up expectations in which they can have confidence, so Post Keynesian economists employ a range of methods and styles of argument, that is, a pluralist methodology.

To the extent that most economists treat uncertainty, if at all, as peripheral, they too have been engaging in denial, suppressing cognitive dissonance. As Gordon (2003: 15) states with respect to the unknowable: '[f]or the positivist, there is only denial'. This 
can be seen as a coping mechanism, but also follows from the dualistic methodological approach which is based on understanding the economy as a closed system buffeted by random shocks and subjected to constraints (especially on information). Because apparently this basic understanding has not fundamentally changed, the uncertainty evident among mainstream economists at the onset of crisis seems to have been dispelled and confidence in theorising restored. But, while denial of uncertainty reduced the uncertainty of most mainstream economists, it has had widespread consequences for the economy. Economists have presented themselves as experts, whose judgements serve to reduce uncertainty among economic agents and policy-makers. Yet in the crisis economists were widely criticised for their failure to predict and then, in the immediate aftermath, explain the crisis. Mainstream economists had compounded the problem of denying uncertainty in their theories by failing to acknowledge the uncertainty attached to their own expertise. There is a conflict between the way in which mainstream economists present themselves and how they are often regarded in society (see further Hayek 1974).

Policy-makers, even when following a course set by mainstream theory, are in a special position. Because they are required to engage with an economy which is conditioned by uncertainty, they have to face up also to their own uncertainty. Indeed speeches by members of the UK's Monetary Policy Committee have frequently referred to uncertainty (see for example King 2010) and the lead for much of the discussion of economists' model uncertainty came from central banks. But, since the theoretical guidance is generally taken from the mainstream, the view taken of uncertainty is in practice very limited. Thus the efforts to promote transparency with respect to central bank thinking presumes that full information is in principle available, while the central 
bank view of risks with respect to forecasts is quantified, e.g. by fan charts. More fundamentally mainstream theory encouraged inattention to the way in which institutions and conventions had previously evolved to promote confidence in money, and financial stability more generally, thus reducing uncertainty. The initial policy response to the crisis presumed a prevalence of calculative rationality with respect to benchmark equilibrium prices rather than the growing awareness of the flimsy basis for market pricing and the prevalence of uncertainty which was undermining trust.

\section{Concluding Remarks: A Non-dualistic Approach to Uncertainty}

Within mainstream economics it is generally implied that uncertainty is by its nature uncomfortable and unwelcome, challenging our liking for order. Choice theory allows for ambiguity aversion as well as risk aversion as a given preference. Indeed we have discussed the response to the experience of uncertainty so far in terms of reducing its damaging effects. This negative view of uncertainty is also evident in the nonmainstream literature that studies the evolution of behaviour and institutions in terms of uncertainty as a central feature of the economic process.

Within a closed-system approach, the mode of thought is dualistic, such that certain knowledge is juxtaposed to its opposite, ignorance/uncertainty. While the new behavioural economics is uncovering evidence of heuristics and biases relative to the rationality benchmark, the challenge ultimately has been to translate these results into the formal deductivist framework (Dow 2012). Uncertainty represents a lack (of certainty or certainty-equivalence) which prevents agents from fully-informed rational optimisation, so that it is seen as anathema (particularly in financial markets). It acts as an impediment 
to the optimal operation of free markets, in much the same way as the exercise of emotion (equated with irrationality and typically viewed as another exogenous disturbance), and thus reduces social welfare.

The Keynesian view of fundamental uncertainty explained above avoids this dualism. Fundamental uncertainty is endogenous in the long and short terms and is open to analysis. Where an absence of quantitative probabilities is the general case, knowledge is subject to uncertainty of varying degrees and relies substantially on judgment. Uncertainty is open to change as a result of institutional change and the emergence of new conventional understandings, including the attitude to uncertainty. The degree to which uncertainty is admitted may change with circumstances.

But how far is the consistent aversion to fundamental uncertainty displayed in mainstream economics ${ }^{7}$ justified on Keynesian grounds? Uncertainty aversion finds some support in the psychology literature where it is often equated with anxiety (Smithson 2008), as well as being identified with quantifiable risk. ${ }^{8}$ But psychology, like economics, is characterised by different schools of thought, such that this is not a universal view of uncertainty in the field. Indeed there is also a view in psychology that uncertainty should not be understood in dualistic terms, but rather as the outcome of creativity, with both positive and negative features. The psychologist Gordon (2003: 96) for example challenges the traditional scientific approach to uncertainty, referring to: 'Prigogine's assertion that uncertainty is an inherent cosmic expression, deeply embedded within the core of reality. The deep psychic expression of this experience is anxiety which $\ldots$ is conceived not as pathology but rather as an essential state of being emerging simultaneously with uncertainty'. 
Gordon explicitly contrasts his view of uncertainty with that which arises from a formal deductivist framework. Creativity is an innate aspect of human nature which is generally regarded in a positive light. It generates a form of uncertainty which is exciting and gives meaning to life. Similarly economists such as Hayek, Knight and Shackle have focused on creativity as central to entrepreneurial activity and in turn to economic growth (Loasby 2011). Competitors are not content with normal profits but continuously seek abnormal profits by creative differentiation from others. This creativity is associated with the pre-conditions for uncertainty, which can be energising rather than debilitating.

While these are the pre-conditions also for entrepreneurship, the entrepreneur is characterised as someone who acts in spite of uncertainty. This is a form of uncertaintydenial which occurs within the open-system understanding of reality within which new opportunities are created and without which no non-routine action would be taken. Similarly semantic uncertainty can act as a spur to new understandings which facilitate innovation (Lane and Maxfield 2005). For economists themselves, uncertainty can act as a spur to innovative theoretical developments. When Smith (1795) wrote of the sense of wonder at novel events as a motivation for science, he did not talk about anxiety or cognitive dissonance in negative terms, which is what uncertainty can promote in a pessimistic environment, but more of the excitement of uncertainty in an optimistic environment.

Within such an open-system framework, uncertainty is shown to be embedded in the decision-making environment. For economists to understand that environment, they need to understand uncertainty. Ignoring uncertainty (including uncertainty denial in the economy) protects the economist from anxiety, but at the cost of failing to understand 
something fundamental to the economy. By embracing the presence of uncertainty, therefore, non-mainstream economists are able to build up knowledge which is precluded from mainstream economics. As a result, by understanding uncertainty, non-mainstream economists are in a better position to address in particular the contexts in which uncertainty may have damaging consequences and develop theories and policy prescriptions designed to reduce it.

But a changed understanding of uncertainty also requires a changed way of thinking in much of economics. The closed-system approach requires resistance to incorporating uncertainty, while uncertainty-denial reinforces the preference for closedsystem thinking. Change would be required at the conceptual level, allowing for the positive aspects of uncertainty for example, as well as the implications of uncertainty for the scope for knowledge. It would also require a move from the monism of mathematical formalism to one of the many possible pluralist methodologies, where a range of methods is employed in order to build up a considered view with the aid of judgement. The outcome would allow for a greater focus on the factors which are central to economic behaviour under uncertainty and thus a greater capacity to address any resulting problems, as well as opportunities. A case in point is the current crisis which could not readily be understood or analysed with existing mainstream theories but which made perfect sense from a Keynes/Minsky perspective which has uncertainty at its core.

The financial crisis arguably stemmed from mechanisms which fostered overconfidence in expectations as to risk and return, that is, inattention to uncertainty. It was argued that the uncertainty-denial adopted by financial markets and by mainstream economists has ultimately been counterproductive, actually increasing uncertainty. 
Further, within a closed-system approach, fundamental uncertainty can only enter as an exogenous distortion, seen in negative terms. But, while uncertainty can at times be debilitating, it can be seen at other times as being the counterpart to creativity and emergence. It is concluded that, rather than recoiling from uncertainty to the extent of not addressing it seriously, economists would do better by accepting its significance and developing methodologies and theories accordingly. The resulting improved understanding of economic processes would in fact serve to reduce the damaging aspects of economists' uncertainty and, potentially, of uncertainty in the economy.

\section{References}

Akerlof, G A (2002) 'Behavioral Macroeconomics and Macroeconomic Behavior', American Economic Review 92 (3): 411-33.

Amargilio, J and Ruccio, D F (1995) 'Keynes, Postmodernism and Uncertainty', in S. C.

Dow and J. Hillard (eds), Keynes, Knowledge and Uncertainty. Aldershot: Edward Elgar.

Bewley, T (2002) 'Knightian Decision- Theory: Part I', Cowles Foundation Paper No. 1053.

Bibow, J (2009) Keynes on Monetary Policy, Finance and Uncertainty: Liquidity Preference Theory and the Global Financial Crisis, London: Routledge.

Bloom, N (2009) 'The Impact of Uncertainty Shocks', Econometrica, 77 (3): 623-85. 
Boyarchenko, N (2102) 'Ambiguity Shifts and the 2007-2008 Financial Crisis', Journal of Monetary Economics, 59: 493-507.

Camerer, C and Weber, M (1992) 'Recent Developments in Modelling Preferences: Uncertainty and Ambiguity', Journal of Risk and Uncertainty 5: 325-70.

Chick, V (1995) '”Order out of Chaos" in Economics?', in S C Dow and J Hillard (eds), Keynes, Knowledge and Uncertainty. Aldershot: Edward Elgar, 25-42.

Chick, V (2008) 'Could the crisis at Northern Rock have been predicted?: An evolutionary approach', Contributions to Political Economy 27: 115-24.

Chick, V (2013) 'The current banking crisis: an evolutionary view', in G C Harcourt and J Pixley (eds), Financial crises and the nature of capitalist money: Mutual developments from the work of Geoffrey Ingham. London: Palgrave Macmillan.

Chick, V and Dow, S C ([2005] 2012) 'The Meaning of Open Systems', Journal of Economic Methodology, 12: 363-81, reprinted in S C Dow, Foundations for New Economic Thinking: a collection of essays. London: Palgrave Macmillan, pp.178-96.

Coase, R H ([1937] 1991) 'The Nature of the Firm', reprinted in O E Williamson and S G Winter, eds, The Nature of the Firm: Origins, Evolution, and Development. Oxford: Oxford University Press, pp. 18-33.

Davidson, P (1972) Money and the Real World. London: Macmillan. 
Dequech, D (2000) Fundamental uncertainty and Ambiguity', Eastern Economic Journal 26 (1): 41-60.

Dow, A C and Dow, S C (2011) 'Animal Spirits Revisited', Capitalism and Society 6(2) article 1, at http://www.bepress.com/cas/vol6/iss2/art1/.

Dow, J and Werlang, S R da C (1992) 'Uncertainty Aversion, Risk Aversion, and the Optimal Choice of Portfolio', Econometrica 60 (1): 197-204.

Dow, S C ([1995] 2012) 'Uncertainty about Uncertainty', in S C Dow and J Hillard (eds), Keynes, Knowledge and Uncertainty. Aldershot: Edward Elgar, 117-27, reprinted in S C Dow, Foundations for New Economic Thinking: a collection of essays. London: Palgrave Macmillan, pp. 72-82.

Dow, S C (2003) 'Economists' Knowledge and the Knowledge of Economic Actors', in J Runde and S Mizuhara (eds), Perspectives on the Philosophy of Keynes's Economics: Probability, Uncertainty and Convention. London: Routledge.

Dow, S C (2004) 'Uncertainty and Monetary Policy’, Oxford Economic Papers, 56: 53961.

Dow, S C (2011) 'Cognition, Sentiment and Financial Instability: Psychology in a Minsky Framework', Cambridge Journal of Economics 35(2): 233-50.

Dow, S C (2012) 'Mark Blaug on Formalism and Reality: the case of behavioural economics', University of Stirling mimeo. 
Dow, S C (2013) 'Keynes on Knowledge, Expectations and Rationality', forthcoming in E S Phelps and R Frydman (eds), Rethinking Expectations: the Way Forward for Macroeconomics. Princeton NJ: Princeton University Press.

Dow, S C, Klaes, M and Montagnoli, A (2007) 'Monetary Policy by Signal', in D G Mayes and J Toporowski (eds), Open Market Operations and the Financial Markets. London: Routledge.

Drechsler, I (2013) 'Uncertainty, Time-Varying Fear, and Asset Prices', Journal of Finance 68 (5): 1843-89. Not in text; model U in asset pmarkets, eqm anal

Earl, P E (1984) The Corporate Imagination: How Big Companies Make Mistakes. Brighton: Wheatsheaf.

Earl, P E ([1992] 2010) 'The Complementarity of Economic Applications of Cognitive Dissonance Theory and Personal Construct Psychology', in S E G Lea, P Webley and B M Young (eds), New Directions in Economic Psychology. Aldershot: Edward Elgar. Updated version accessible at http://shredecon.files.wordpress.com/2010/09/cepdissonance.pdf

Earl, P E (2012) 'Kahneman's Thinking, Fast and Slow from the Standpoint of Old Behavioural Economics', presented to the annual HETSA Conference, http://www.hetsa.org.au/hetsa2012/abstracts_index.html

Ellsberg, D (1961) 'Risk, Ambiguity and the Savage Axioms'. Quarterly Journal of Economics 65: 743-9. 
Feduzi, A, Runde, J and Zappia, C (2012) 'De Finetti on the insurance of risks and uncertainties', British Journal for the Philosophy of Science, 63(2): 329-56.

Frydman, R and Goldberg, M (2011) Beyond Mechanical Markets: Asset Price Swings, Risk and the Role of the State. Princeton, NJ: Princeton University Press.

Gigerenzer, G (2007) Gut Feelings: The Intelligence of the Unconscious. New York: Viking Press.

Gordon, K (2003) 'The Impermanence of Being: Toward a Psychology of Uncertainty', Journal of Humanistic Psychology, 43 (2): 96-117.

Hansen, L P and Sargent, T J (2001). 'Acknowledging misspecification in macroeconomic theory', Review of Economic Dynamics 4: 519-35.

Hayek F A (1960) The Constitution of Liberty. London: Routledge \& Kegan Paul.

Hayek F A (1973-9) Law, Legislation and Liberty, 3 vols. London: Routledge \& Kegan Paul.

Hayek, F A (1974) 'The Pretence of Knowledge', Nobel Prize Lecture, accessible at http://www.nobelprize.org/nobel_prizes/economics/laureates/1974/hayek-lecture.html

Hodgson, G M (1988) Economics and Institutions. Cambridge: Polity Press.

Jefferson, M (2012) 'Shell scenarios: What really happened in the 1970s and what may be learned for current world prospects', Technological Forecasting \& Social Change 79: $186-97$. 
Kahneman, D and Tversky, A (1974) 'Judgment under Uncertainty: Heuristics and Biases', Science 185: 1124-31.

Keynes, J M ([1921] 1973) A Treatise on Probability, Collected Writings vol. VIII. London: Macmillan, for the Royal Economic Society

Keynes, J M ([1926] 1972) 'The End to Laissez-faire', in Essays in Persuasion. Collected Writings of John Maynard Keynes, vol. IX. London: Macmillan, pp. 270-94.

Keynes, J M ([1936] 1973) The General Theory of Employment, Interest and Money. Collected Writings volume VII. London: Macmillan, for the Royal Economic Society.

Keynes, J M ([1937] 1973) 'The General Theory of Employment', Quarterly Journal of Economics 51, 209-23, reprinted in The General Theory and After, Part II: Defence and Development, Collected Writings, vol. XIV. London: Macmillan for the Royal Economic Society.

King, M (2010) ‘Uncertainty in Macroeconomic Policy Making: Art or Science?', speech delivered to the Royal Society Conference, London, 22 March.

Knight, F H (1921) Risk, Uncertainty and Profit. Boston, MA: Hart, Schaffner \& Marx; Houghton Mifflin \& Co.

Lane, D and Maxfield, R (2005) 'Ontological Uncertainty and Innovation', Journal of Evolutionary Economics, 15: 3-50. 
Lawson, T (1988) 'Probability and uncertainty in economics analysis', Journal of Post Keynesian Economics, 11 (1): 38-65.

Lawson, T (1997) Economics and Reality. London: Routledge.

Lawson, T (2009) 'The current economic crisis: its nature and the course of academic economics', Cambridge Journal of Econonomics, 33(4): 759-77.

Loasby, B J (2011) 'Uncertainty and imagination, illusion and order: Shackleian connections', Cambridge Journal of Economics 35 (4): 771-83.

MacKenzie, D (2006) 'Is Economics Performative? Option Theory and the Construction of Derivatives Markets', Journal of the History of Economic Thought 28(1): 29-55.

Minsky, H P (1986) Stabilizing an Unstable Economy. New Haven: Yale University Press.

Runde, J (1995) 'Risk, uncertainty and Bayesian decision theory: a Keynesian view', in S C Dow and J Hillard (eds), Keynes, Knowledge and Uncertainty. Aldershot: Edward Elgar, 197-210.

Runde, J (1990) 'Keynesian uncertainty and the weight of arguments', Economics and Philosophy 6: 275-92.

Runde, J (2009) 'Dissecting the Black Swan', Critical Review 21(4): 491-505.

Shackle, G L S (1968) A Scheme of Economic Theory. Cambridge: Cambridge University Press. Not in text 
Simon, H (1955) 'A Behavioral Model of Rational Choice' Quarterly Journal of Economics 69 (1): 99-118.

Simon, H (1986) 'Rationality and Psychology in Economics', Journal of Business 59 (4:2): 5209-24.

Skidelsky, R (2009) Keynes: The Return of the Master by Robert Skidelsky Allen Lane. Not in text

Skidelsky, R (2011) 'The relevance of Keynes', Cambridge Journal of Economics, 35 (1): 1-13. Not in text

Smith, A ([1795] 1980) 'The History of Astronomy', in Essays on Philosophical Subjects, edited by W L D Wightman. Oxford: Oxford University Press, pp. 33-105.

Smithson, M (2008) 'Psychology's ambivalent view of uncertainty', in G Bammer and M Smithson, eds, Uncertainty and Risk: Multidisciplinary Perspectives. London: Earthscan, pp. 205-218.

Stiglitz, J (2010) 'The Non-existent Hand', London Review of Books, 32 (8), 22 April.

Taffler, R and Tuckett, D (2007) 'Emotional Finance: Understanding what Drives Investors', Professional Investor, Autumn: 19-20.

Tily, G (2007) Keynes's General; Theory, the Rate of Interest and 'Keynesian' Economics: Keynes Betrayed. London: Palgrave Macmillan. 
Townshend, H (1937) 'Liquidity-premium and the theory of value', Economic Journal 47 (March): 157-69.

Tuckett, D (2011) Minding the Markets: an emotional finance view of financial instability. London: Palgrave Macmillan.

Tuckett, D, Chong, K and Ruatti, C (2012) 'Re-thinking Uncertainty', University College London mimeo.

Weber, E U and Johnson, E J (2008) 'Decisions under uncertainty: Psychological, economic, and neuroeconomic explanations of risk preference', in $\mathrm{P}$ Glimcher, $\mathrm{C}$ Camerer, E Fehr and R Poldrack, eds, Neuroeconomics: Decision making and the brain. New York: Elsevier.

Whalen, C J (2007) 'The U.S. Credit Crunch of 2007: A Minsky Moment', Levy Institute Public Policy Brief no. 92.

\footnotetext{
${ }^{1}$ See Lawson (1988) for a careful exploration of epistemic and aleatory uncertainty in economics.

${ }^{2}$ See Chick and Dow (2005) for a full specification of the conditions for closure.

${ }^{3}$ This possibility of asymmetric information underpinned Akerlof's (2002) introduction to behavioural macroeconomics.
} 
${ }^{4}$ These bounds might apply to the taking in of evidence; Shackle (1968: 67) introduced the notion of expectational time as a mechanism for abstracting from the passage of real time, thus reducing uncertainty.

${ }^{5}$ A similar argument could be developed with respect to anxiety, as an enabling emotion.

${ }^{6}$ The contrast being drawn here between regarding uncertainty as a normal condition of knowledge on the one hand and as ignorance on the other parallels Kant's misunderstanding of Hume's skepticism as being destructive of science.

${ }^{7}$ We have seen that there is less aversion now to addressing the more limited sense of uncertainty which results from asymmetric information.

${ }^{8}$ In the interface between psychology and economics, it is common to find the equation of uncertainty with quantifiable risk (Weber and Johnson 2008). 